\title{
Conformational Behavior of Cyanoacetic Acid: A Combined Matrix Isolation Fourier Transform Infrared Spectroscopy and Theoretical Study
}

\author{
Igor D. Reva, ${ }^{* \dagger}$ Stepan G. Stepanian, Ludwik Adamowicz, ${ }^{\S}$ and Rui Fausto ${ }^{\dagger}$ \\ Department of Chemistry, University of Coimbra, 3004-535 Coimbra, Portugal, Institute for Low-Temperature \\ Physics and Engineering, National Academy of Sciences of Ukraine, 47 Lenin Ave., 61164, Kharkov, Ukraine, \\ and Department of Chemistry, University of Arizona, Tucson, Arizona 85721
}

Received: January 30, 2003; In Final Form: June 9, 2003

\begin{abstract}
This work reports the first experimental study of the cyanoacetic acid (CAA) monomer. Samples of CAA were isolated in low-temperature argon, krypton, and xenon matrixes and characterized using FTIR spectroscopy. Annealing experiments revealed the presence of different conformers in the matrixes. The direct interconversion of the gauche-cis $(g c)$ into the cis-cis $(c c)$ conformer was observed upon annealing of matrixes before formation of aggregates. The use of different matrix host gases enabled separation of the observed conformational effects from the site-splitting of IR absorptions. The assignment of the experimental spectra was based on both the annealing results and the comparison of the experimental data with results of theoretical calculations performed at the B3LYP/aug-cc-pVTZ level of theory. The relative energies of the observed conformers, as well as the transition states separating these forms, were calculated at the MP2, MP4, QCISD, and CCSD levels of theory with the aug-cc-pVxZ $(x=\mathrm{D}, \mathrm{T}$, and $\mathrm{Q})$ basis sets. The planar $c c$ conformer was found to be the lowest energy form of CAA. The second conformer, with a nonplanar backbone, $g c$, is doubly degenerated by symmetry and was predicted to be $1.3 \mathrm{~kJ} \mathrm{~mol}^{-1}$ (ZPVE corrected CCSD/augcc-VTZ energies) less stable than the $c c$ form. In matrixes a fraction of the $g c$ conformer undergoes geometrical distortion toward the planar trans-cis $(t c)$ structure, which in the gaseous phase corresponds to the saddle point between the two mirror $g c$ forms.
\end{abstract}

\section{Introduction}

In this paper we report the results of a combined structural and vibrational study of cyanoacetic acid (CAA) monomer by matrix isolation infrared spectroscopy and molecular orbital calculations. This work comes in the line of our previous studies on other carboxylic acids that show conformational isomerism.

Low-temperature matrix isolation is nowadays a wellestablished method of studying conformational isomerization processes. ${ }^{1,2}$ Previously we observed experimentally that glycine is capable of undergoing intramolecular isomerization in lowtemperature matrixes. ${ }^{3}$ We found that the three lowest energy conformers of glycine could be successfully trapped in argon matrixes only when the substrate temperature was $13 \mathrm{~K}$ or lower. At higher substrate temperatures the direct interconversion of conformer III into the minimum-energy conformer $\mathbf{I}$ occurred.

Cyanoacetic acid $\left(\mathrm{NC}-\mathrm{CH}_{2}-\mathrm{COOH}\right)$ is structurally similar to glycine $\left(\mathrm{H}_{2} \mathrm{~N}-\mathrm{CH}_{2}-\mathrm{COOH}\right)$, differing only by the substituent at the $\alpha$-carbon atom. As glycine, cyanoacetic acid has two conformers separated by a low energy gap (about $3.1 \mathrm{~kJ} \mathrm{~mol}^{-1}$ as predicted by Hartree-Fock 6-31G* calculations ${ }^{4}$ ). Under such conditions, a substantial amount of each conformer is expected in the gas-phase equilibrium at room temperature. By analogy with glycine, for the samples prepared at low temperature of the optical substrate, identification of both conformers of CAA by matrix-isolation IR spectroscopy is expected to be possible.

The specific aim of this work is a detailed structural and vibrational characterization of cyanoacetic acid monomer. To

\footnotetext{
* Corresponding author. E-mail: reva@qui.uc.pt.

¿ University of Coimbra.

National Academy of Sciences of Ukraine.

$\S$ University of Arizona.
}

the best of our knowledge, there is no published experimental data on the structure or the spectra of this molecule either in the gaseous phase or in matrixes. The present study provides first information on these properties for this system.

\section{Experimental Details}

Commercial cyanoacetic acid (99\%, Aldrich) was used in the present study. Cyanoacetic acid is a highly hygroscopic compound and, if exposed to atmosphere, absorbs water. This is easily visible in the transformation of the dry solid into wet crystals. However, the adsorbed water could be easily removed from the compound by several hours of pumping immediately before the matrix experiment. Both visual control of the sample before deposition (dry solid) and analysis of the obtained spectra were used to test if the amount of residual water in matrixes is negligible. Argon N60, krypton N48, and xenon N45 were supplied by Air Liquid and used without further purification.

The low-temperature equipment was based on an APD Cryogenics closed-cycle helium refrigerator with a DE-202A expander. The IR spectra were registered in the range 4000$400 \mathrm{~cm}^{-1}$ using a Mattson (Infinity 60AR Series) Fourier transform infrared spectrometer with a DTGS detector and a $\mathrm{Ge} / \mathrm{KBr}$ beam-splitter, with resolution of $0.5 \mathrm{~cm}^{-1}$. Rare gases were deposited from room temperature at a rate of about 10 $\mathrm{mmol} \mathrm{h}^{-1}$. Cyanoacetic acid was sublimated at $296 \mathrm{~K}$ from a Knudsen cell through a SS-4BMRG (NUPRO) needle valve. The deposition rate of the compound was chosen low enough to ensure that the species trapped in matrixes was an almost exclusively monomeric CAA. A CsI window was used as the optical substrate for matrixes. 


\section{Theoretical Methods}

The equilibrium geometries of the selected conformers were fully optimized at the DFT and MP2 levels with standard augcc-pVDZ and aug-cc-pVTZ basis sets. The DFT calculations were carried out with the three-parameter density functional abbreviated as B3LYP, which includes Becke's gradient exchange correction, ${ }^{5}$ the Lee, Yang, Parr correlation functional, ${ }^{6}$ and the Vosko, Wilk, and Nusair ${ }^{7}$ correlation functional.

The geometry optimizations were followed by frequency calculations to check the nature of the stationary points found in the optimizations. No imaginary frequencies were obtained for the $c c$ and $g c$ conformers, and one imaginary frequency was obtained for the $t c$ conformation (for definition of the conformers see the next section). The calculated frequencies were also used to assist the analysis of the experimental spectra and to account for the zero-point vibrational energy (ZPVE) corrections. Because the relative stability of the cyanoacetic acid conformers is of special interest in this study, we performed additional energy calculations for the $c c, g c$, and $t c$ species at the MP2/ aug-cc-pVQZ level, as well as at the MP4(SDQ), ${ }^{8}$ QCISD, ${ }^{9}$ and $\mathrm{CCSD}^{10,11}$ levels of theory with the aug-cc-pVDZ and aug-ccpVTZ basis sets. The transition state separating the $c c$ and $g c$ conformers was also located using both the DFT and MP2 methods. All calculations in this work were done on SGI ORIGIN 2000 and IBM Power 3 workstations using the Gaussian 98 program. ${ }^{12}$

\section{Results and Discussion}

Relative Stabilities of the Cyanoacetic Acid Conformers. The conformers of cyanoacetic acid may be structurally characterized using two torsion parameters: the $\mathrm{O}=\mathrm{COH}$ dihedral angle, with possible values around $0^{\circ}$ and $180^{\circ}$ corresponding to the cis and trans orientation of the $\mathrm{O}-\mathrm{H}$ and $\mathrm{C}=\mathrm{O}$ groups, and the $\mathrm{CCC}=\mathrm{O}$ dihedral angle, which describes the orientation of the carboxyl group with respect to the cyano group. The possible values of this torsion are around $0^{\circ}$ (cis orientation) and $\pm 120^{\circ}$ (gauche orientation). The conformers with different gauche orientations are mirror structures, corresponding to degenerate states with identical IR spectral characteristics. The two gauche forms are separated by a saddle point corresponding to the trans orientation of the $\mathrm{CCC}=\mathrm{O}$ dihedral $\left(180^{\circ}\right)$. Assuming that the NCC fragment in cyanoacetic acid is nearly linear, the $\mathrm{CCC}=\mathrm{O}$ and $\mathrm{O}=\mathrm{COH}$ dihedral angles define completely the conformational space of the molecule. We use a two-letter designation for the possible conformers, where the first letter, $c$ (cis), $t$ (trans), or $g$ (gauche), describes the value of the $\mathrm{CCC}=\mathrm{O}$ angle and the second letter, $c$ (cis) or $t$ (trans), defines the $\mathrm{O}=\mathrm{COH}$ coordinate.

A preliminary attempt to identify the possible conformers of cyanoacetic acid was carried out at the standard MP2/6$31++\mathrm{G}^{* *}$ level of theory, and four minima were located. After accounting for the ZPVE, conformer $c c$ was found to be the lowest energy form, whereas conformer $g c$ was predicted to be slightly less stable by only $0.6 \mathrm{~kJ} \mathrm{~mol}^{-1}$. Scheme 1 shows the structures of the $c c$ and $g c$ conformers and the atom numbering used in this work. Conformer $c c$ has $C_{s}$ symmetry, and $g c$ belongs to the $C_{1}$ point group, due to its nonplanar heavy-atom framework. Two additional, slightly nonplanar conformers with the $\mathrm{O}=\mathrm{COH}$ fragment in the trans orientation were also located on the potential energy surface of cyanoacetic acid. These correspond to the high energy $t t$ and $c t$ forms, which are respectively 19.3 and $30.9 \mathrm{~kJ} \mathrm{~mol}^{-1}$ less stable than the $c c$ conformer. As follows from the relative energies, only the $c c$ and $g c$ conformers are relevant to the present experimental study.
SCHEME $1^{a}$

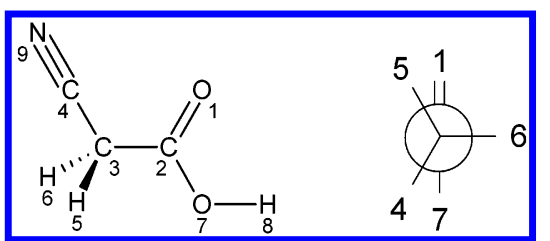

${ }^{a}$ Left: atom numbering for the $c c$ conformer of cyanoacetic acid. All atoms are planar except $\mathrm{H} 5$ and $\mathrm{H} 6$ symmetrically situated above and below the plane of the molecule. Right: a Newman projection along the $\mathrm{C} 3-\mathrm{C} 2$ axis in the $g c$ conformer.

On the basis of the above theoretical results, we selected three structures $(c c, g c$, and $t c)$ for further calculations. Here $g c$ and $c c$ are unique conformers corresponding to the low-energy minima on the cyanoacetic acid potential energy surface and $t c$ is a transition state separating the two mirror $g c$ conformers. The relative stabilities of these structures were calculated at several advanced levels of theory, and the results are summarized in Table 1. The main aim of these calculations was to obtain the energy difference between the studied conformations with maximal possible accuracy and to establish how the level of theory and basis set employed influence the calculated results.

The geometries of the $c c$ and $g c$ conformers were fully optimized at the B3LYP/aug-cc-pVDZ and B3LYP/aug-ccpVTZ levels. The optimization was followed by frequency calculations to account for the ZPVE. In both cases the $c c$ conformer was found to be the lowest energy form (Table 1). The predicted energy difference calculated with the aug-ccpVDZ basis set is $0.52 \mathrm{~kJ} \mathrm{~mol}^{-1}$, whereas using the larger augcc-pVTZ basis set reduces this value to only $0.31 \mathrm{~kJ} \mathrm{~mol}^{-1}$. Next, we reoptimized the geometries of the conformers at the MP2 level of theory using the same basis sets. Comparing to the DFT results, the energy difference calculated at the MP2 level is higher $\left(0.86\right.$ and $0.94 \mathrm{~kJ} \mathrm{~mol}^{-1}$ for the two basis sets) and in this case, opposite to DFT, increasing the basis set leads to an increase of the energy gap between the conformers. Additional calculations performed at the MP2/aug-cc-pVQZ level of theory at the MP2/aug-cc-pVTZ geometries led to a small increase of the conformational energy difference by 0.02 $\mathrm{kJ} \mathrm{mol}^{-1}$. Finally, we calculated the relative stabilities of the $c c$ and $g c$ conformers at the MP4, QCISD, and CCSD levels of theory with the aug-cc-pVDZ and aug-cc-pVTZ basis sets using the MP2/aug-cc-pVTZ optimized geometries. The obtained results are also summarized in Table 1. As can be seen from the table, the $c c$ conformer is predicted to be the lowest energy form at all levels of theory, and an increase of accuracy of the calculations systematically leads to an increase of the relative energy of the $g c$ form. For all advanced levels of theory, the calculations with a triply split valence basis set predict a larger energy difference than those performed with a doubly split basis set. However, the relative energy of the $g c$ form never exceeds $1.3 \mathrm{~kJ} \mathrm{~mol}^{-1}$, with the energy difference obtained at the highest theoretical level used, CCSD/aug-cc-pVTZ, being $1.29 \mathrm{~kJ} \mathrm{~mol}^{-1}$. Such an energy difference is small, and thus, the presence of both conformers in matrixes can be expected.

The tc structure corresponds to the top of the barrier separating the two equivalent-by-symmetry $g c$ forms. At the MP2/aug-cc-pVDZ level the energy gap between the $t c$ and $g c$ forms was estimated as $0.47 \mathrm{~kJ} \mathrm{~mol}^{-1}$, whereas the highestlevel calculations predicted it in the range of $0.75-0.98 \mathrm{~kJ} \mathrm{~mol}^{-1}$ (these energy differences include ZPVE corrections excluding the lowest frequency for both $g c$ and $t c$ structures, which corresponds to the torsion around the $\mathrm{CC}$ bond, i.e., the reaction coordinate for the $g c \rightarrow t c \rightarrow g c^{\prime}$ interconversion). 
TABLE 1: Energies (Atomic Units) of the Lowest Energy Conformer $c c$ and Relative Stabilities Including the Zero Point Vibrational Energy $\left(\mathrm{kJ} \mathrm{mol}^{-1}\right)$ of the Cyanoacetic Acid Conformers Calculated at the Different Levels of Theory

\begin{tabular}{lccc}
\hline \multicolumn{1}{c}{ method } & $E_{g c}-E_{c c}$ & $E_{t c}-E_{g c}{ }^{a}$ & $E_{c c}$ \\
\hline DFT(B3LYP)/6-31++G** & 0.35 & 0.04 & -321.277791 \\
DFT(B3LYP)/aug-cc-pVDZ & 0.52 & 0.27 & -321.365946 \\
DFT(B3LYP)/aug-cc-pVTZ & 0.31 & 0.30 & -321.447274 \\
MP2/6-31++G** & 0.55 & 1.37 & -320.407114 \\
MP2/aug-cc-pVDZ & 0.86 & 0.54 & -320.534370 \\
MP2/aug-cc-pVTZ & 0.94 & 0.49 & -320.800252 \\
& For MP2/aug-cc-pVTZ Geometries (ZPVE from DFT(B3LYP)/aug-cc-pVTZ): & -320.888498 \\
MP2/aug-cc-pVQZ & 0.96 & 0.47 & -320.555065 \\
MP4(sdq)/aug-cc-pVDZ & 1.03 & 0.89 & -320.809364 \\
MP4(sdq)/aug-cc-pVTZ & 1.12 & 0.76 & -320.555514 \\
QCISD/aug-cc-pVDZ & 1.16 & 0.89 & -320.808528 \\
QCISD/aug-cc-pVTZ & 1.24 & 0.75 & -320.551781 \\
CCSD/aug-cc-pVDZ & 1.19 & 0.98 & -320.804530 \\
CCSD/aug-cc-pVTZ & 1.29 & 0.83 &
\end{tabular}

${ }^{a}$ The lowest frequencies were excluded both for $t c$ and $g c$ forms.

TABLE 2: Optimized Geometry Parameters (Ångstroms and Degrees), Rotational Constants (MHz), and Dipole Moments (Debye) Calculated at MP2/aug-cc-pVTZ and DFT(B3LYP)/aug-cc-pVTZ Levels for Cyanoacetic Acid $c c$ and $g c$ Conformers

\begin{tabular}{|c|c|c|c|c|}
\hline & \multicolumn{2}{|c|}{ MP2/aug-cc-pVTZ } & \multicolumn{2}{|c|}{ DFT(B3LYP)/aug-cc-pVTZ } \\
\hline & $c c$ & $g c$ & $c c$ & $g c$ \\
\hline \multicolumn{5}{|c|}{ Bond Lengths } \\
\hline $\mathrm{C} 2=\mathrm{O}$ & 1.204 & 1.207 & 1.196 & 1.200 \\
\hline $\mathrm{C} 2-\mathrm{C} 3$ & 1.515 & 1.517 & 1.522 & 1.525 \\
\hline $\mathrm{C} 3-\mathrm{C} 4$ & 1.454 & 1.457 & 1.455 & 1.456 \\
\hline $\mathrm{C} 3-\mathrm{H} 5$ & 1.090 & 1.087 & 1.092 & 1.089 \\
\hline $\mathrm{C} 3-\mathrm{H} 6$ & 1.090 & 1.092 & 1.092 & 1.093 \\
\hline $\mathrm{C} 2-\mathrm{O}$ & 1.352 & 1.345 & 1.351 & 1.342 \\
\hline $\mathrm{O}-\mathrm{H}$ & 0.970 & 0.971 & 0.969 & 0.969 \\
\hline $\mathrm{C} 4-\mathrm{N} 9$ & 1.170 & 1.170 & 1.148 & 1.149 \\
\hline \multicolumn{5}{|c|}{ Bond Angles } \\
\hline $\mathrm{C} 3-\mathrm{C} 2=\mathrm{O}$ & 126.4 & 124.0 & 126.5 & 123.0 \\
\hline $\mathrm{C} 4-\mathrm{C} 3-\mathrm{C} 2$ & 112.4 & 113.5 & 113.7 & 115.7 \\
\hline $\mathrm{H} 5-\mathrm{C} 3-\mathrm{C} 2$ & 108.5 & 108.0 & 108.5 & 107.5 \\
\hline $\mathrm{H} 6-\mathrm{C} 3-\mathrm{C} 2$ & 108.5 & 107.6 & 108.5 & 107.0 \\
\hline $\mathrm{C} 3-\mathrm{C} 2-\mathrm{O}$ & 109.1 & 111.4 & 109.4 & 112.5 \\
\hline $\mathrm{C} 2-\mathrm{O}-\mathrm{H}$ & 106.3 & 106.6 & 107.5 & 107.8 \\
\hline $\mathrm{C} 3-\mathrm{C} 4-\mathrm{N} 9$ & 179.3 & 179.5 & 179.1 & 179.4 \\
\hline \multicolumn{5}{|c|}{ Dihedral Angles } \\
\hline $\mathrm{C} 4-\mathrm{C} 3-\mathrm{C} 2=\mathrm{O}$ & 0.0 & 140.6 & 0.0 & 151.2 \\
\hline $\mathrm{H} 5-\mathrm{C} 3-\mathrm{C} 2=\mathrm{O}$ & 122.1 & 261.1 & 122.5 & 272.9 \\
\hline $\mathrm{H} 6-\mathrm{C} 3-\mathrm{C} 2=\mathrm{O}$ & 237.9 & 17.8 & 237.5 & 27.7 \\
\hline $\mathrm{C} 4-\mathrm{C} 3-\mathrm{C} 2-\mathrm{O}$ & 180.0 & 320.8 & 180.0 & 331.4 \\
\hline $\mathrm{O}=\mathrm{C} 1-\mathrm{O}-\mathrm{H}$ & 0.0 & -0.5 & 0.0 & -0.6 \\
\hline $\mathrm{N} 9-\mathrm{C} 4-\mathrm{C} 3-\mathrm{C} 2$ & 180.0 & 179.8 & 180.0 & 179.6 \\
\hline \multicolumn{5}{|c|}{ Dipole Moments ${ }^{a}$} \\
\hline & 5.26 & 2.79 & 4.93 & 2.54 \\
\hline \multicolumn{5}{|c|}{ Rotational Constants } \\
\hline$A$ & 10138.28 & 3893.59 & 10238.00 & 9313.93 \\
\hline$B$ & 2272.18 & 2363.45 & 2250.89 & 2339.80 \\
\hline$C$ & 1877.50 & 999.74 & 1866.17 & 1949.81 \\
\hline
\end{tabular}

${ }^{a}$ MP2 dipole moments were calculated with keyword "density $=$ current".

It is also interesting to compare the calculated geometries of the $c c$ and $g c$ conformers of cyanoacetic acid (Table 2). The main structural differences occur in the $\mathrm{C}=\mathrm{O}$ and $\mathrm{C}-\mathrm{O}$ bond lengths, which in the $g c$ conformer are longer and shorter, respectively, in comparison with the $c c$ conformer, and in the $\mathrm{C}-\mathrm{C}=\mathrm{O}$ and $\mathrm{C}-\mathrm{C}-\mathrm{C}$ angles. The $\mathrm{C}-\mathrm{C}-\mathrm{C}$ angle is larger in $g c$ due to the repulsion between the cyano group and the lone electron pairs of the hydroxylic oxygen, and the increase in this angle is compensated by a reduction in the $\mathrm{C}-\mathrm{C}=\mathrm{O}$ angle, which is larger in $c c$ (note that the $\mathrm{O}=\mathrm{C}-\mathrm{O}$ angle is nearly equal in the two conformers). On the other hand, the relative values of the $\mathrm{C}=\mathrm{O}$ and $\mathrm{C}-\mathrm{O}$ bond lengths in the two conformers indicate that the $\left[-\mathrm{C}(=\mathrm{O})-\mathrm{OH} \leftrightarrow-\mathrm{C}\left(-\mathrm{O}^{-}\right)=\mathrm{O}^{+} \mathrm{H}\right]$ mesomerism within the carboxylic group is more important in $g c$ than in $c c$, as can be expected by considering the proximity of the electron-rich cyano group to the hydroxyl oxygen and the proximity of one of the methylene hydrogen atoms to the carbonyl oxygen in the $g c$ conformer. The longer and shorter $\mathrm{C}=\mathrm{O}$ and $\mathrm{C}-\mathrm{O}$ bond lengths in $g c$ relative to $c c$ correlate well with the relative observed frequencies for the $\mathrm{C}=\mathrm{O}$ and $\mathrm{C}-\mathrm{O}$ stretching modes in the two conformers; the first appearing at lower frequencies and the second at higher frequencies (Table 3).

As mentioned in the Introduction, the structure of cyanoacetic acid in the gaseous phase has not yet been studied experimentally. The calculated structural parameters, dipole moments, and rotational constants of the cyanoacetic acid monomers reported in Table 2 may serve as useful information in future electron diffraction or microwave studies of the compound.

Experimental Matrix-Isolation FTIR Spectra. Fragments of the infrared spectra of cyanoacetic acid isolated in krypton and xenon matrixes are presented in Figure 1. Only one band due to the carbonyl stretching vibration is expected to appear in this range for each conformer. Detection of two features, separated by ca. $10 \mathrm{~cm}^{-1}$, suggests the presence of two conformers in the matrixes deposited at $8.3 \mathrm{~K}$ (solid line in Figure 1). However, matrix site effects or aggregates could manifest themselves also as split bands. The presence of the aggregates in the samples could be easily excluded by comparison of the observed spectra of freshly deposited samples with those obtained after annealing to high temperatures (above $30 \mathrm{~K}$ ). For example, in argon matrixes aggregate bands were observed at 3537.6, 3526.4, 1793.2, 1780.5, 1769.5, 1382.5, $1311.3,1169.5,1138.0$, and $860.2 \mathrm{~cm}^{-1}$. On the other hand, to examine the possibility of the observed band-splitting being due to the matrix site-splitting effect, several samples were deposited using identical temperature conditions into different matrix gas hosts (Ar, $\mathrm{Kr}$, and $\mathrm{Xe}$ ). In each matrix the spectrum exhibits roughly twice the number of absorptions in comparison to what is expected for a single conformer. Annealing of the samples at moderate temperatures (ca. $20 \mathrm{~K}$ ) results in almost complete disappearance of one set of absorptions and in the simultaneous growth of the other set (dashed line in Figure 1). The use of different matrixes does not allow us to prove or disprove that the presence of different matrix sites is responsible for the splitting. It might be possible that similar site-splittings occur for a certain vibration in different matrixes. However, observa- 
6354 J. Phys. Chem. A, Vol. 107, No. 33, 2003

TABLE 3: Observed and Calculated [DFT(B3LYP)/aug-cc-pVTZ] Vibrational Frequencies and IR Intensities of the Cyanoacetic Acid Conformers ${ }^{a}$

\begin{tabular}{|c|c|c|c|c|c|c|c|c|c|c|c|}
\hline \multicolumn{8}{|c|}{ observed $^{b}$} & \multirow{2}{*}{\multicolumn{4}{|c|}{ calculated }} \\
\hline \multicolumn{3}{|c|}{$\mathrm{Ar}$} & \multicolumn{2}{|c|}{$\mathrm{Kr}$} & \multicolumn{2}{|c|}{$\mathrm{Xe}$} & \multirow[b]{2}{*}{$\operatorname{assgnt}^{f}$} & & & & \\
\hline$\omega^{c}$ & $\mathrm{~S} / \mathrm{U}^{d}$ & $I^{e}$ & $\omega^{c}$ & $I^{e}$ & $\omega^{c}$ & $I^{e}$ & & $v^{g}$ & int $^{h}$ & $\mathrm{PED}^{i}$ & assgnt \\
\hline 3573.9 & $\mathrm{~S}$ & & & & & & $c c$ & & & $2 \mathrm{OH} \mathrm{s}$ & \\
\hline 3563.9 & $\mathrm{~S}$ & & & & & & $c c$ & & & & \\
\hline 3560.5 & $\mathrm{~S}$ & 26.15 & 3545.6 & 24.92 & 3531.4 & 110.60 & $c c$ & 3588 & 90.1 & OH s [100] & $c c$ \\
\hline 3559.0 & $\mathrm{U}$ & & & & & & $c c$ & & & & \\
\hline 3555.3 & $\mathrm{U}$ & & & & & & $g c$ & & & & \\
\hline 3553.5 & $\mathrm{U}$ & 20.76 & 3541.1 & 14.13 & 3523.0 & 58.55 & $g c$ & 3584 & 88.3 & OH s [100] & $g c$ \\
\hline \multirow[t]{3}{*}{3550.1} & $\mathrm{~S}$ & & 3533.9 & & & & $t c$ & 3583 & 88.1 & OH s [100] & tc \\
\hline & & & & & & & & 2985 & 1.0 & C3H5 s [91] & $g c$ \\
\hline & & & & & & & & 2968 & 1.6 & $\mathrm{CH}_{2} \mathrm{~s}$ asym [100] & $t c$ \\
\hline \multirow[t]{2}{*}{2967.0} & & 1.52 & & & & & & 2962 & 1.0 & $\mathrm{CH}_{2} \mathrm{~s}$ asym [100] & $c c$ \\
\hline & & & & & & & & 2937 & 2.4 & $\mathrm{CH}_{2}$ s sym [100] & $t c$ \\
\hline 2942.8 & & 2.06 & & & & & & 2931 & 1.8 & $\mathrm{CH}_{2} \mathrm{~s}$ sym $[100]$ & $c c$ \\
\hline & & & & & & & & 2925 & 2.6 & C3H6 s [91] & $g c$ \\
\hline & & & & & & & & 2280 & 4.2 & C4N9 s [100] & $c c$ \\
\hline & & & & & & & & 2273 & 6.0 & C4N9 s [68] & $t c$ \\
\hline & & & & & & & & 2272 & 6.8 & C4N9 s [100] & $g c$ \\
\hline 1799.8 & & sh & & & & & $c c$ & & & & \\
\hline 1797.8 & $\mathrm{U}$ & 37.32 & 1797.3 & 32.06 & 1792.0 & 127.96 & $c c$ & 1798 & 285.3 & C2O1 s [85] & $c c$ \\
\hline 1795.3 & $\mathrm{~S}$ & & 1795.6 & & & & $c c$ & & & & \\
\hline 1791.1 & $\mathrm{U}$ & & 1785.2 & & & & $g c$ & 1784 & 395.8 & $\mathrm{C} 2 \mathrm{O} 1 \mathrm{~s}$ [88] & $g c$ \\
\hline 1786.3 & $\mathrm{~S}$ & 86.68 & 1782.0 & 46.12 & 1780.0 & 130.09 & $t c$ & 1780 & 396.1 & C2O1 s [88] & $t c$ \\
\hline 1783.9 & & & 1777.3 & & 1777.6 & & $t c$ & & & & \\
\hline 1778.5 & & & 1774.8 & & & & & & & & \\
\hline 1414.0 & & 0.43 & 1410.5 & 0.33 & 1404.1 & 2.37 & $g c$ & 1416 & 7.6 & $\mathrm{CH}_{2} \mathrm{~b}[89]$ & $g c$ \\
\hline & & & & & & & & 1412 & 4.6 & $\mathrm{CH}_{2}$ b [90] & tc \\
\hline 1403.2 & & 4.24 & 1400.5 & 4.55 & 1394.5 & 23.65 & $c c$ & 1413 & 20.7 & $\mathrm{CH}_{2} \mathrm{~b}[92]$ & $c c$ \\
\hline & & & 1399.0 & & & & $c c$ & & & & \\
\hline 1377.9 & $\mathrm{U}$ & & & & & & $c c$ & & & & \\
\hline 1374.7 & $\mathrm{~S}$ & 13.02 & 1376.2 & 9.55 & 1373.7 & 32.54 & $c c$ & 1357 & 63.6 & $\mathrm{CH}_{2}$ b [30], C2C3 s [18], C2O7 s [17] & $c c$ \\
\hline & & & 1366.1 & & & & $g c$ & 1335 & 65.4 & $\mathrm{OH}$ b [39], C2O7 s[25], O1C2C3 b[15], C2C3 s[12] & $t c$ \\
\hline 1362.1 & & 7.04 & 1363.5 & 6.09 & 1359.7 & 15.90 & $g c$ & 1333 & 64.1 & $\mathrm{OH}$ b [38], C2O7 s [25], O1C2C3 b [16] & $g c$ \\
\hline 1355.2 & & & 1360.6 & & & & $g c$ & & & & \\
\hline & & & & & 1325.3 & 2.72 & & & & & \\
\hline 1297.6 & & 0.14 & 1302.0 & 0.11 & & & & 1305 & 2.8 & $\mathrm{CH}_{2} \mathrm{~b}[82]$ & $t c$ \\
\hline 1292.3 & & 0.32 & 1290.6 & 0.10 & & & & 1301 & 2.0 & $\mathrm{CH}_{2} \mathrm{~b}[81]$ & $g c$ \\
\hline 1284.4 & & 1.29 & & & & & & & & & \\
\hline 1266.5 & & 0.36 & 1271.5 & 0.86 & & & & 1274 & 0.8 & $\mathrm{OH} \mathrm{b}[46], \mathrm{CH}_{2}$ b [34] & $c c$ \\
\hline & & & 1220.0 & 0.29 & & & & 1221 & 0.2 & $\mathrm{CH}_{2} \mathrm{~b}[76], \mathrm{O} 1 \mathrm{C} 2 \mathrm{C} 3 \mathrm{C} 4 \mathrm{t}[15]$ & $t c$ \\
\hline 1215.7 & & 2.55 & 1214.7 & 1.90 & 1216.6 & 1.75 & $g c$ & 1216 & 12.9 & $\mathrm{CH}_{2} \mathrm{~b}[67]$ & $g c$ \\
\hline 1211.9 & & 2.76 & 1210.4 & 2.23 & $\begin{array}{l}1209.7 \\
1206.0\end{array}$ & 16.19 & $c c$ & 1210 & 0.3 & $\mathrm{CH}_{2} \mathrm{~b}[96]$ & $c c$ \\
\hline 1161.9 & $\mathrm{~S}$ & 7.05 & 1161.6 & 4.21 & 1156.1 & 6.06 & $t c$ & 1156 & 238.5 & $\mathrm{OH} \mathrm{b} \mathrm{[46],} \mathrm{C2O7} \mathrm{s} \mathrm{[36]}$ & $t c$ \\
\hline 1148.2 & $\mathrm{U}$ & & 1146.5 & 18.47 & 1142.4 & 65.82 & $g c$ & 1148 & 219.3 & $\mathrm{OH}$ b [39], C2O7 s [35] & $g c$ \\
\hline 1144.0 & $\mathrm{U}$ & 20.08 & 1143.1 & & & & $g c$ & & & & \\
\hline 1126.7 & $\mathrm{~S}$ & & 1124.3 & & & & $c c$ & & & & \\
\hline 1125.7 & $\mathrm{~S}$ & 44.90 & 1121.4 & 37.50 & 1120.1 & 151.61 & $c c$ & 1117 & 313.1 & $\mathrm{C} 2 \mathrm{O} 7 \mathrm{~s}$ [48], OH b [24] & $c c$ \\
\hline 1123.6 & $\mathrm{U}$ & & 1114.3 & & 1118.0 & & $c c$ & & & & \\
\hline 1121.4 & $\mathrm{U}$ & & 1109.9 & & & & $c c$ & & & & \\
\hline 1118.8 & $\mathrm{U}$ & & & & & & $c c$ & & & & \\
\hline 972.8 & $\mathrm{U}$ & 0.39 & 978.0 & 0.52 & 974.4 & 1.08 & $c c$ & 966 & 12.9 & $\mathrm{C} 3 \mathrm{C} 4 \mathrm{~s}[51]$ & $c c$ \\
\hline 969.8 & $\mathrm{~S}$ & 0.59 & 972.0 & 1.25 & 970.4 & 6.26 & $c c$ & 964 & 1.5 & $\mathrm{C} 3 \mathrm{C} 4 \mathrm{~s}$ [73] & $t c$ \\
\hline 965.0 & & 0.49 & & & 962.2 & 0.25 & & 959 & 1.7 & $\mathrm{C} 3 \mathrm{C} 4 \mathrm{~s}[74]$ & $g c$ \\
\hline 936.5 & & 1.30 & 936.1 & 0.94 & 932.9 & 7.09 & $c c$ & 939 & 6.0 & $\mathrm{CH}_{2} \mathrm{~b}[100]$ & $c c$ \\
\hline & & & 935.2 & & & & $c c$ & & & & \\
\hline 933.0 & $\mathrm{U}$ & 0.33 & 931.7 & 0.60 & 930.7 & & $g c$ & 935 & 5.6 & $\mathrm{CH}_{2} \mathrm{~b}[92]$ & $g c$ \\
\hline 931.3 & $\mathrm{~S}$ & 0.54 & & & 929.0 & 2.16 & $t c$ & 934 & 4.7 & $\mathrm{CH}_{2} \mathrm{~b}[60], \mathrm{H} 5 \mathrm{C} 3 \mathrm{C} 2 \mathrm{O} 7 \mathrm{t}[26]$ & $t c$ \\
\hline 865.7 & & 0.98 & 865.6 & 1.36 & 866.2 & 5.33 & $c c, g c$ & 844 & 15.8 & $\mathrm{C} 2 \mathrm{C} 3 \mathrm{~s}[50], \mathrm{C} 2 \mathrm{C} 3 \mathrm{C} 4 \mathrm{~b}$ [24] & $c c$ \\
\hline 853.7 & & 0.45 & 853.8 & 0.74 & 853.9 & 4.42 & $c c, g c$ & 842 & 9.0 & C2C3 s [39], C2O7 s [32], C2C3C4 b [19] & $g c$ \\
\hline 841.2 & & 0.32 & & & & & & 832 & 9.0 & $\mathrm{C} 2 \mathrm{C} 3 \mathrm{~s}$ [41], C2O7 s [33], C2C3C4 b [18] & tc \\
\hline 664.7 & & 1.55 & 660.6 & 7.88 & 663.7 & 24.22 & $g c$ & 676 & 76.6 & $\mathrm{OH}$ t [51], O1C2C3C4 t [13] & $g_{c}$ \\
\hline & & & & & & & & 673 & 101.4 & $\mathrm{OH}$ t [86], O1C2C3C4 t [15] & $t c$ \\
\hline 651.8 & & sh. & & & & & & & & & \\
\hline 646.6 & & 10.40 & 647.6 & 3.80 & 646.6 & 15.80 & $c c$ & 640 & 27.7 & $\mathrm{OH} \mathrm{t}[90]$ & $c c$ \\
\hline 618.3 & & 18.76 & 617.0 & 13.45 & 615.4 & 50.50 & $c c$ & 637 & 94.5 & $\mathrm{O} 1 \mathrm{C} 2 \mathrm{C} 3 \mathrm{~b}$ [48], C2C3C4 b [25] & $c c$ \\
\hline 614.5 & & 0.84 & & & & & $c c$ & & & & \\
\hline & & & & & & & & 616 & 52.3 & C3C2O7 b [43], C2C3C4 b [37] & $t c$ \\
\hline 607.2 & & 2.66 & 608.2 & 4.90 & 604.5 & 35.27 & $g c$ & 614 & 76.7 & $\mathrm{OH}$ t [35], C3C2O7 b [26] & $g c$ \\
\hline 594.1 & & & & & & & & 519 & 24.5 & $\mathrm{O} 1 \mathrm{C} 2 \mathrm{C} 3 \mathrm{C} 4 \mathrm{t}$ [73], H5C3C2O t [13], OH t [10] & $t c$ \\
\hline
\end{tabular}


TABLE 3 (Continued)

\begin{tabular}{|c|c|c|c|c|c|c|c|c|c|c|c|}
\hline \multicolumn{8}{|c|}{ observed $^{b}$} & \multirow{2}{*}{\multicolumn{4}{|c|}{ calculated }} \\
\hline \multicolumn{3}{|c|}{$\mathrm{Ar}$} & \multicolumn{2}{|c|}{$\mathrm{Kr}$} & \multicolumn{2}{|c|}{$\mathrm{Xe}$} & \multirow[b]{2}{*}{ assgnt ${ }^{f}$} & & & & \\
\hline$\omega^{c}$ & $\mathrm{~S} / \mathrm{U}^{d}$ & $I^{e}$ & $\omega^{c}$ & $I^{e}$ & $\omega^{c}$ & $I^{e}$ & & $v^{g}$ & int $^{h}$ & $\mathrm{PED}^{i}$ & assgnt \\
\hline 521 & & & 519 & & 519.8 & 8.04 & $g c$ & 519 & 28.8 & $\mathrm{H} 5 \mathrm{C} 2 \mathrm{C} 3 \mathrm{O} 7 \mathrm{t}[44], \mathrm{O} 1 \mathrm{C} 2 \mathrm{C} 3 \mathrm{~b}[16]$ & $g c$ \\
\hline \multirow[t]{2}{*}{510.8} & & 5.34 & 510.6 & & 510.7 & 20.22 & $c c$ & 513 & 25.1 & $\mathrm{C} 2 \mathrm{C} 3 \mathrm{t}[34], \mathrm{OH} \mathrm{t}[10]$ & $c c$ \\
\hline & & & & & & & & 484 & 10.9 & $\mathrm{O} 1 \mathrm{C} 2 \mathrm{C} 3 \mathrm{~b}[39], \mathrm{C} 2 \mathrm{C} 3 \mathrm{~s}$ [27], C2C3C4 b [20] & $t c$ \\
\hline \multirow[t]{14}{*}{469.6} & & & & & 465.8 & 5.51 & & 474 & 8.2 & $\mathrm{C} 2 \mathrm{C} 3 \mathrm{C} 4 \mathrm{~b}[28], \mathrm{O} 1 \mathrm{C} 2 \mathrm{C} 3 \mathrm{~b}[26], \mathrm{C} 2 \mathrm{C} 3 \mathrm{~s}$ [17] & $g c$ \\
\hline & & & & & 460.8 & & & 460 & 15.2 & C3C2O7 b [39], C2C3C4 b [29], C2C3 s [17] & $c c$ \\
\hline & & & & & & & & 377 & 4.4 & C3C2O7 b [40], C3C4N9 b [22], O1C2C3C4 t [22] & gc \\
\hline & & & & & & & & 375 & 2.9 & $\mathrm{C} 3 \mathrm{C} 2 \mathrm{O} 7$ b [32], O1C2C3C4 t [28], C3C4N9 b [20], O1C2C3 b [11] & $t c$ \\
\hline & & & & & & & & 370 & 3.1 & $\mathrm{C} 3 \mathrm{C} 2 \mathrm{O} 7 \mathrm{~b}[36], \mathrm{C} 3 \mathrm{C} 4 \mathrm{~N} 9 \mathrm{~b}[24], \mathrm{O} 1 \mathrm{C} 2 \mathrm{C} 3 \mathrm{~b}[22]$ & $c c$ \\
\hline & & & & & & & & 350 & 0.2 & $\mathrm{O} 1 \mathrm{C} 2 \mathrm{C} 3 \mathrm{C} 4 \mathrm{t}$ [54], O1C2C $3 \mathrm{H} 6 \mathrm{t}$ [13] & $g c$ \\
\hline & & & & & & & & 349 & 0.0 & $\mathrm{O} 1 \mathrm{C} 2 \mathrm{C} 3 \mathrm{C} 4 \mathrm{t}[98]$ & $c c$ \\
\hline & & & & & & & & 346 & 0.1 & $\mathrm{O} 1 \mathrm{C} 2 \mathrm{C} 3 \mathrm{C} 4 \mathrm{t}$ [32], O1C2C3H5 t [11], O1C2C3H6 t [11] & $t c$ \\
\hline & & & & & & & & 156 & 7.2 & $\mathrm{C} 2 \mathrm{C} 3 \mathrm{C} 4 \mathrm{~b}[46], \mathrm{C} 2 \mathrm{C} 3 \mathrm{C} 4 \mathrm{~N} 9 \mathrm{t}[32]$ & $t c$ \\
\hline & & & & & & & & 155 & 6.5 & C3C4N9 b [49], C2C3C4N9 t [43] & $g c$ \\
\hline & & & & & & & & 151 & 2.0 & C2C3C4N9 t [46], C3C4N9 b [41] & $c c$ \\
\hline & & & & & & & & 43 & 4.3 & O7C2C3H5 t [39], O7C2C3H6 t [39] & $c c$ \\
\hline & & & & & & & & 21 & 11.4 & $\mathrm{O} 7 \mathrm{C} 2 \mathrm{C} 3 \mathrm{H} 5 \mathrm{t}[44]$ & $g c$ \\
\hline & & & & & & & & -20 & 14.6 & $\mathrm{O} 1 \mathrm{C} 2 \mathrm{C} 3 \mathrm{C} 4 \mathrm{t}[-41]$ & $t c$ \\
\hline
\end{tabular}

${ }^{a}$ Abbreviations: sh, shoulder; s, stretching; b, bending; t, torsion. ${ }^{b}$ The experimental data immediately after deposition at $8 \mathrm{~K}$ in $\mathrm{Ar}, \mathrm{Kr}$, and $\mathrm{Xe}$ matrixes. ${ }^{c}$ Observed frequencies $\left(\mathrm{cm}^{-1}\right) .{ }^{d} \mathrm{~S}$, states for stable matrix site in argon; U, states for unstable matrix site in argon. ${ }^{e}$ Relative integral intensities (arbitrary units). ${ }^{f}$ Empirical assignment based on the annealing behavior (Note: according to our experimental data the $t c$ structure in the matrix corresponds to a minimum, whereas in the gaseous phase has it one negative frequency, thus being a first-order saddle point. In most cases the experimental frequencies of the $t c$ form are not distinguishable from those due to the $g c$ conformer. Assignment to the $t c$ applies only to the argon matrix and is different from the $g c$; see text.) ${ }^{g}$ Calculated frequencies $\left(\mathrm{cm}^{-1}\right.$, scaled applying scaling factors of 0.96 for $\mathrm{OH}$, $\mathrm{CH}$, and $\mathrm{CN}$ stretching vibrations and 0.98 for all other vibrations). ${ }^{h}$ Calculated intensity $\left(\mathrm{km} \mathrm{mol}^{-1}\right) .{ }^{i}$ Potential energy distributions $(\%$, contributions with less than $10 \%$ are not listed).

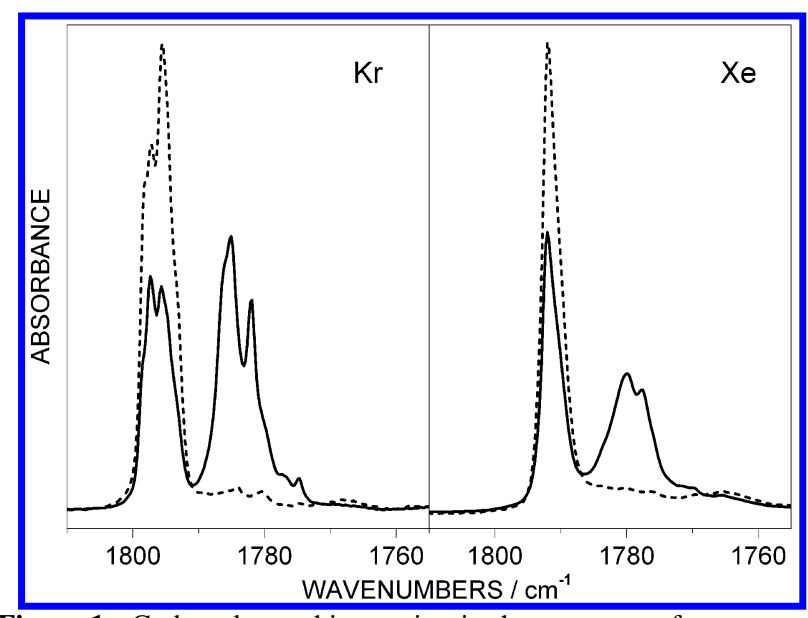

Figure 1. Carbonyl stretching region in the spectrum of cyanoacetic acid isolated in krypton and xenon matrixes. (Solid line) spectra immediately after deposition at the lowest possible substrate temperature $(8.3 \mathrm{~K})$. (Dashed line) spectra after annealing of matrixes at $20 \mathrm{~K}$.

tion of identical band splitting patterns for each spectral region in three different matrixes provides a good reason to state that the observed effects result from trapping of different conformers in the matrixes. This claim is further confirmed by the good overall agreement found between the observed bands and their theoretically predicted positions in the entire spectrum. This particularly concerns the relative frequencies of the bands due to the $c c$ and $g c$ forms in the experiment and in the calculations, as discussed in detail below.

The spectra of the $c c$ and $g c$ forms were calculated at several levels of theory. The best agreement between the simulated and the experimental data was obtained at the DFT(B3LYP)/augcc-PVTZ level. The theoretical results obtained at this level are presented in Table 3, along with the experimental data for cyanoacetic acid isolated in argon, krypton, and xenon matrixes. The assignment of the spectra was based on the predicted relative frequencies for the two conformers and on the behavior of the samples during annealing. The detailed comparison of the experimental data with the simulated data leaves no doubt that it is the $c c$ conformer that prevails in the matrixes after annealing. The analysis of the most important observed characteristic absorptions are described below.

In the carbonyl stretching region the lower frequency component was found to disappear upon annealing of krypton and xenon matrixes (Figure 1), thus it was assumed to belong to $g c$. Accordingly, the theory predicts the carbonyl stretching vibration in the $g c$ form to be $14 \mathrm{~cm}^{-1}$ lower than in the $c c$ conformer. Note that the calculated splitting reproduces well the experimental value of about $10 \mathrm{~cm}^{-1}$ observed in all the matrixes. This observation is also in agreement with the longer calculated $\mathrm{C}=\mathrm{O}$ bond length in $g c$ than in $c c$.

The spectrum of cyanoacetic acid isolated in argon requires a more detailed description. The region of the carbonyl stretching vibration is presented in Figure 2 and in the animated GIF image included in the Supporting Information (Figure 1S). The spectrum registered immediately after matrix deposition at 8.3 K (upper trace in Figure 2 and the first frame in the animated picture Figure 1S) exhibits only absorptions above $1775 \mathrm{~cm}^{-1}$. As we have shown previously for benzoic acid, ${ }^{13,14}$ the absorptions due to associated species of carboxylic acids in the carbonyl stretching region are usually red-shifted by $20-50$ $\mathrm{cm}^{-1}$ with respect to the monomer. Our freshly deposited samples do not have any absorption bands from 1770 to 1670 $\mathrm{cm}^{-1}$ and do not produce any new bands during annealing up to $16 \mathrm{~K}$. The features situated between 1793 and $1773 \mathrm{~cm}^{-1}$ disappear after annealing and cannot be attributed to associates. Thus all the changes in the spectra observed upon annealing up to $16 \mathrm{~K}$ must result from monomer effects. The manifestation of associates can be easily traced by further annealing of the matrixes. Heating of the matrix to $32 \mathrm{~K}$ (see Figure $1 \mathrm{~S}$ ) results in the appearance in the spectrum of new broad features centered approximately at $1768.5,1749.5$, and $1740.5 \mathrm{~cm}^{-1}$, exactly 


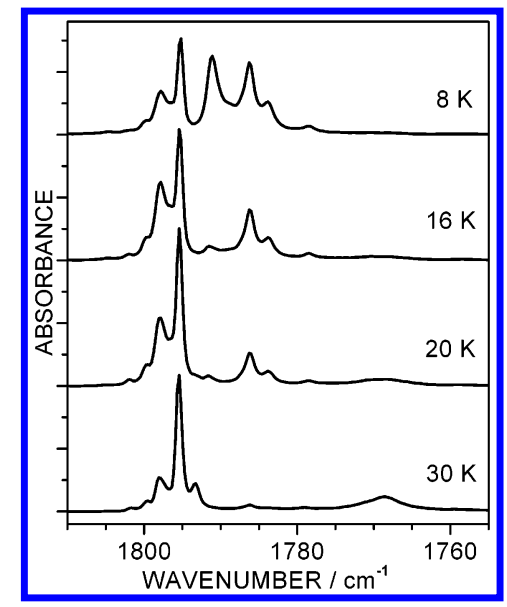

Figure 2. Carbonyl stretching region in the spectrum of cyanoacetic acid isolated in an argon matrix. The upper spectrum is collected immediately after matrix deposition at the lowest possible substrate temperature $(8.3 \mathrm{~K})$. Subsequent spectra (shifted for clarity) are recorded after annealing of the same sample.

where bands due to associates are expected to appear. A weak band centered at $1793.4 \mathrm{~cm}^{-1}$, which appears at high matrix temperatures and grows concomitantly with the absorptions in the $1770-1740 \mathrm{~cm}^{-1}$ region, is also ascribable to the associates.

The bands due to the monomeric species are more relevant to the present study and deserve further description. In argon, similarly to $\mathrm{Kr}$ and $\mathrm{Xe}$ matrixes, the relative intensities of the peaks lying between 1793 and $1775 \mathrm{~cm}^{-1}$ decrease upon annealing and we attribute the origin of this multiplet to the $g c$ conformer. Traces of this form disappear after annealing to 30 $\mathrm{K}$ but are still present in the argon matrix annealed to $20 \mathrm{~K}$ (Figure 2) in contrast to samples isolated in krypton or xenon matrixes annealed to the same $20 \mathrm{~K}$ (Figure 1). The absorptions that grow at frequencies confined between 1793 and $1801 \mathrm{~cm}^{-1}$ are due to the most stable $c c$ conformer.

It should be noted that besides the above-discussed conformational band splitting, splitting due to different matrix packing sites is also observed. It gives rise to a multiplet structure of features for each conformer. In the carbonyl stretching region, the matrix site splitting ranges from 2 and $3 \mathrm{~cm}^{-1}$ in the xenon and krypton matrixes (Figure 1) to more than $5 \mathrm{~cm}^{-1}$ in argon (Figure 2). In argon, in contrast to xenon and krypton, annealing of the site-split components does not occur uniformly. The highest frequency component of the $g c$ related absorption centered at $1791.1 \mathrm{~cm}^{-1}$ disappears almost completely at $16 \mathrm{~K}$ and, during the early stage of the annealing, converts preferentially into a high-frequency component of the $c c$ band centered at $1797.8 \mathrm{~cm}^{-1}$ (Figure 2). We believe that these high-frequency components are due to less favorable packing sites. In Table 3, the two different packing sites are specified as "S" (stable) and "U" (unstable) for the experimental data obtained in argon. After reaching $16 \mathrm{~K}$, we cooled the matrix back to $8 \mathrm{~K}$ and found that the spectroscopic changes due to the annealing of the samples are irreversible. The further annealing of the matrix affects the stable packing sites for each of the conformers: the band at $1786.3 \mathrm{~cm}^{-1}$ of the $g c$ form decreases in favor of the $1795.3 \mathrm{~cm}^{-1}$ absorption of the $c c$ conformer. At $18 \mathrm{~K}$ (Figure 1S) the formation of dimer bands starts to be discernible. At that stage of the annealing, the stable packing site of the $c c$ conformer is becoming more populated at the expenses of both $g c$ and the less stable packing site of the $c c$ form itself. Hence, the band at $1795.3 \mathrm{~cm}^{-1}$ reaches its maximum intensity at about 20-22 K (Figure 2) and then starts to decrease due to formation of aggregates (the animated picture in Figure 1S, presented as

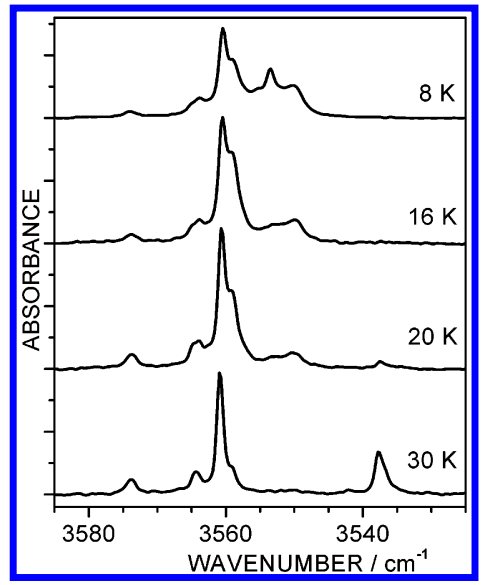

Figure 3. OH stretching region in the spectrum of cyanoacetic acid isolated in an argon matrix. The upper spectrum is collected immediately after matrix deposition at the lowest possible substrate temperature (8.3 K). Subsequent spectra (shifted for clarity) are recorded after annealing of the same sample.

Supporting Information, clearly demonstrates all these effects). At a temperature of about $30 \mathrm{~K}$ (Figure 2) the $g c$ related features disappear completely and the band centered at $1795.3 \mathrm{~cm}^{-1}$, due to the stable packing site of the $c c$ monomer, dominates in the spectrum. This demonstrates that the $c c$ monomer is still present in the matrix in a substantial amount, though at this temperature it coexists with aggregates.

The next very characteristic vibration is the $\mathrm{OH}$ stretching. The theoretically predicted splitting between the $\mathrm{OH}$ stretching bands due to $c c$ and $g c$ is $4 \mathrm{~cm}^{-1}$. The band due to the $c c$ conformer appears at a higher frequency (Table 3). The experimental $\mathrm{OH}$ stretching frequencies in argon differ by several $\mathrm{cm}^{-1}$ (from 7 to $10 \mathrm{~cm}^{-1}$, depending on the type of packing). The effect of the annealing on the $\mathrm{OH}$ stretching spectral region is shown in Figure 3 and in the animated GIF image submitted as Supporting Information (see Figure 2S). The changes follow the same pattern as described for the $\mathrm{C}=\mathrm{O}$ stretching region. The following features can be easily recognized: (i) the disappearance of the $g c$-related absorptions at $3553.5 \mathrm{~cm}^{-1}$ (fast annealing, unstable site) and at $3550.1 \mathrm{~cm}^{-1}$ (stable site); (ii) the absorptions due to the stable $\left(3560.5 \mathrm{~cm}^{-1}\right)$ and unstable sites $\left(3559.0 \mathrm{~cm}^{-1}\right)$ of the $c c$ conformer; (iii) the band appearing at ca. $18 \mathrm{~K}$ due to aggregates $\left(3537.7 \mathrm{~cm}^{-1}\right)$. During the annealing, the weak band at $3573.9 \mathrm{~cm}^{-1}$ follows the same behavior as the $3560.5 \mathrm{~cm}^{-1}$ band of the $c c$ conformer in its stable packing site. We assign this feature to the first overtone of the $1795.3 \mathrm{~cm}^{-1}$ absorption $(\mathrm{C}=\mathrm{O}$ stretching band $)$ of the $c c$ conformer.

The frequency ratio (3573.9/1795.3) between the first overtone and the fundamental $\mathrm{C}=\mathrm{O}$ stretching vibration is equal to 1.9907. It is interesting to note that a similar anharmonicity was observed earlier for the $t c$ conformer of pyruvic acid ${ }^{15}$ and for both conformers of formic acid isolated in argon. ${ }^{16,17}$ For pyruvic acid, the observed frequency ratio (3584.2/1799.5) was equal to 1.9917 , whereas for formic acid it was equal to 1.9894 (3519.0/1768.9 and 3515.7/1767.2, equal for the two different packing sites!) and 1.9898 (3595.4/1806.9), respectively, for the most stable and the less stable conformers. This observation may be useful in the search of anharmonic absorptions for other carboxylic acids. For example, the previously observed and not assigned absorption at $3543 \mathrm{~cm}^{-1}$ for glycine isolated in argon ${ }^{18}$ seems to be a good candidate for the first overtone of the 1779 $\mathrm{cm}^{-1}$ carbonyl stretching vibration in the glycine $\mathbf{I}$ conformer with the corresponding anharmonicity factor being equal to 


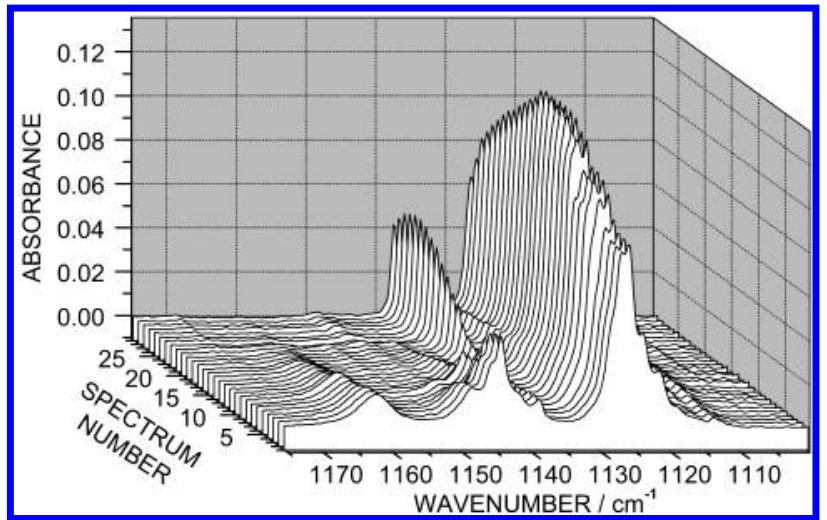

Figure 4. $\mathrm{C}-\mathrm{O}$ stretching $+\mathrm{COH}$ bending region in the spectrum of cyanoacetic acid isolated in an argon matrix. The traces are assigned with consecutive numbers from 1 (front spectrum) to 29 (rear spectrum): 1, spectrum immediately after deposition of the sample at the lowest possible substrate temperature $(8.3 \mathrm{~K}) ; 2-7$, annealing of the sample with the gradual increase of temperature from 10 to $16 \mathrm{~K}$; 8 , sample cooled back to $8.3 \mathrm{~K}$ (reversibility check); 9 , sample annealed to $16 \mathrm{~K}$ again; $10-28$, annealing of the sample in steps of $2 \mathrm{~K}$ from 16 to $32 \mathrm{~K}$, two spectra recorded in average at each intermediate temperature; 29 , final step of annealing, matrix at $32 \mathrm{~K}$.

1.9916. The average value of all the above listed anharmonicity coefficients is ca. 1.99. We tried to apply this empirical coefficient in searching for possible bands of the first overtone of the carbonyl stretching vibration in the $g c$ conformer. The target overtone frequencies were produced at 3554.7 and 3564.3 $\mathrm{cm}^{-1}$, for the stable and unstable packing sites, respectively, of this form. These frequencies coincide with positions of the fundamental $\mathrm{OH}$ stretching vibrations of the $g c$ and $c c$ conformers, further complicating the analysis of this region in the experimental spectrum. However, the observed behavior of the spectrum during annealing of the samples leaves no doubts about the assignments. A reliable estimation of the frequencies of the overtones due to the carbonyl stretching may be useful for predicting the target wavelengths in the case of selective infrared irradiation experiments in the matrix isolated carboxylic acids. ${ }^{19}$

The next very characteristic spectral region is confined between 1170 and $1100 \mathrm{~cm}^{-1}$. It is shown in Figure 4 and in the Supporting Information as an animated GIF image (see Figure 3S). The band appearing at $1137.8 \mathrm{~cm}^{-1}$ at elevated temperatures is easily attributed to associates. For each conformer only one, but very strong, band is predicted in this region (Table 3) due to a vibration that can be described as a mixture of the $\mathrm{C}-\mathrm{O}$ stretching and $\mathrm{COH}$ bending modes. In experiments three distinct bands appear in this region. The multiplet band with complicated shape observed between 1130 and $1120 \mathrm{~cm}^{-1}$ has an annealing pattern consistent with its assignment to the $c c$ conformer (separation of the components of this feature due to the stable and unstable $c c$ packing sites is not as clear as for the bands due to the carbonyl and hydroxyl stretching vibrations discussed above). On the other hand, the calculations predict that the corresponding vibration in the $g c$ form should appear at $1148 \mathrm{~cm}^{-1}$ (Table 3). In the experimental spectra, the annealing behavior of the complex band appearing between 1138 and $1152 \mathrm{~cm}^{-1}$ favors the assignment of this feature to the $\mathrm{gc}$ conformer in its unstable packing site, whereas the band at $1161.9 \mathrm{~cm}^{-1}$ corresponds to the same vibration for the more stable packing site. It shall be noticed that the difference between the frequencies of the two packing sites of the $g c$ conformer is particularly large (ca. $20 \mathrm{~cm}^{-1}$ ), which indicates that the different packing in the two sites induces relatively important geometrical changes in the trapped molecule. Because the most flexible internal coordinate in CAA corresponds to the torsion around the $\mathrm{C}-\mathrm{C}$ bond, it appears to be plausible that the molecules originated from the gas-phase $g c$ conformer and that trapping in the two different sites differs mainly in this geometrical parameter. It seems also plausible to assume that the molecules trapped in one of these sites keep a conformation identical to that existing in the gaseous phase $(g c)$, whereas the other molecules have a different conformation that is stabilized by the matrix.

As a logical candidate for such a conformational species we chose the $t c$ form, corresponding to the saddle point separating the two symmetrically equivalent $g c$ conformers. To confirm this assignment, the spectrum of the $t c$ form was calculated and we compared the experimental spectrum of the minor conformer, disappearing after annealing, with the theoretically predicted spectra for the $g c$ and $t c$ forms. It appeared that the spectrum of the unstable packing site of the minor conformer matches better the theoretical spectrum of the $g c$ form, whereas the spectrum of the stable packing site resembles better the spectrum of the $t c$ form. For instance, the $t c$ absorption (stable site) shows a higher blue shift, with respect to the $c c$ band, than the $g c$ (unstable site), both in the predicted spectra and in the experiment. Such a comparison was carried out not only in the $1170-1100 \mathrm{~cm}^{-1}$ region but also throughout the entire spectrum. Reverting now back to the already discussed carbonyl stretching region, the introduction into the analysis of the $t c$ conformer explains very well the observed spectral peculiarities. In particular, the position of the $t c$ band (stable packing site), shows a higher red shift with respect to the $c c$ carbonyl stretching frequency than the unstable-site-related $g c$ form, according to both the theoretical predictions and the experiment. In fact, whenever the theoretical frequencies of the $g c$ and $t c$ forms are different, there is always splitting of the bands due to the minor conformer in the experiment. Thus, it can be concluded that the $g c$ gas-phase precursor gives rise to two conformations in matrix: $g c$, as an unstable site, and $t c$, as a more stable site.

Analysis of the changes occurring in the region between 1130 and $1180 \mathrm{~cm}^{-1}$ upon changing the matrix gas reveals that, despite the positions of the two features due to the minor conformer being shifted only slightly by the change of the matrix gas from argon to xenon, the relative intensity of the $g c$ with respect to the $t c$ band changes as 2.85:4.39:10.86 in the row Ar:Kr:Xe. Assuming that the structures corresponding to each packing site are essentially the same in all matrixes, the increase of the population of the less stable site from argon to xenon may be explained in several ways: (i) the molecule trapped in the unstable site has a geometry that is not able to fit well to the geometrically more constraining argon matrix cage; (ii) the molecule trapped in the unstable site has a larger dipole moment, which leads to more efficient trapping in more polarizable matrixes.

As already mentioned, the theoretical calculations indicated that in the gaseous phase the energy barrier, i.e., the energy difference between the $g c$ and $t c$ conformations, is very small, less than $1 \mathrm{~kJ} \mathrm{~mol}^{-1}$ (Table 1). So, in a matrix, the small increase of the conformational energy associated with a distortion of the $g c$ geometry toward a more planar heavy-atom backbone $(t c)$ can be easily compensated by a better fit of the molecule to the plane of the closely packed atoms of the matrix host. In other words, a smaller perturbation of the host lattice structure by a nearly planar guest may force the molecule to assume a configuration that better fits the matrix cavity. In such a situation, the matrix defines the more stable conformation, which may be different from its gaseous precursor. This interpretation 


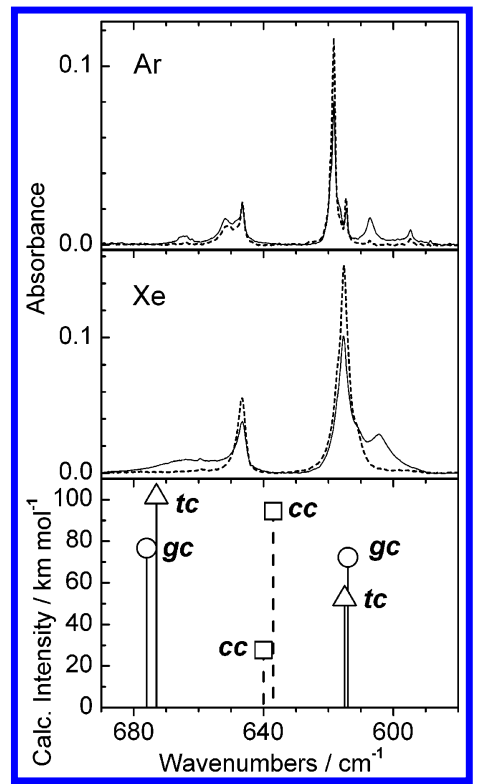

Figure 5. Comparison of the spectra of cyanoacetic acid isolated in an argon (upper panel) and xenon matrix (middle panel) with calculations at the DFT(B3LYP)/aug-cc-pVTZ level (lower panel). Experimental data: (solid lines) spectra immediately after deposition at the lowest possible substrate temperature $(8.3 \mathrm{~K})$; (dashed lines) spectra after annealing of matrixes at $20 \mathrm{~K}$. Calculated data: (dashed bars with squares) $c c$ conformer; (solid bars with circles) $g c$ conformer; (solid bars with triangles) $t c$ conformer.

is further supported by the fact that the calculated dipole moment for $g c$ (2.79 D at MP2/aug-cc-pVTZ level; see Table 2) is larger than that of $t c(2.16 \mathrm{D}$ at the same level) leading to, as observed, an increased population of the less stable trapping site in the more polarizable matrixes.

It is also interesting to mention that a similar behavior was observed in our recent study on methylcyanoacetate. ${ }^{20}$ The spectrum of the higher energy conformer trapped in the matrixes was found to match better the predicted spectrum for the planar trans structure (which, in the gas phase, corresponds to the transition state for the interconversion process between the two mirror-identical gauche forms) than that of the gauche form, pointing to a higher stability of the trans conformation relative to the gauche conformation in the matrixes.

In summary, cyanoacetic acid is expected to exist in the gasphase as the $c c$ and $g c$ conformers; in matrixes the $g c$ form can be trapped partially as an unstable species (that converts easily to other forms early during annealing) or evolve into the $t c$ form, which is apparently stabilized by allowing a better matrix packing. The population ratio of the two forms trapped in the matrixes depends on the matrix host properties, with the less polarizable and smaller argon atoms favoring the trapping of the less polar and more planar $t c$ species.

The region between 680 and $580 \mathrm{~cm}^{-1}$ (Figure 5) also exhibits strong characteristic absorptions, corresponding to the $\mathrm{OH}$ torsion and the OCO bending modes (or mixtures of these two modes). In the spectra in argon, according to the annealing pattern, the bands at 664.7 and $607.2 \mathrm{~cm}^{-1}$ are attributed to the $g c$ conformer (unstable site) whose counterpart bands in xenon appear at 663.7 and $604.5 \mathrm{~cm}^{-1}$ (Figure 5). The $\mathrm{gc}$ stable (or tc) bands are clearly observed at $651.8 / 648.3$ and $594.7 \mathrm{~cm}^{-1}$ in argon. As expected, in xenon the corresponding absorptions are relatively less intense, are broadened, and are situated underneath the more intense bands due to the other forms. These bands are predicted (Table 3) to appear near 675 and $615 \mathrm{~cm}^{-1}$ in both $g c$ and $t c$ forms; i.e., they are separated by $62 \mathrm{~cm}^{-1}$,

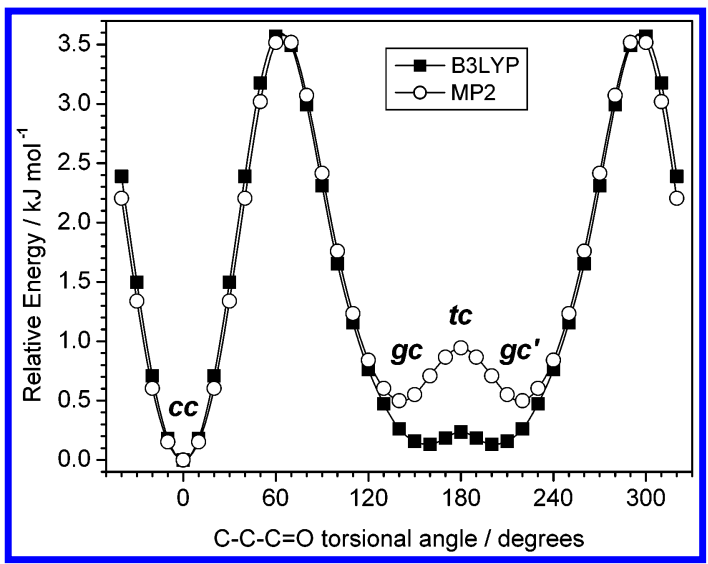

Figure 6. Potential energy profile for the internal $\mathrm{C}-\mathrm{C}-\mathrm{C}=\mathrm{O}$ rotation in cyanoacetic acid, calculated at the MP2/aug-cc-pVDZ (open circles) and the DFT(B3LYP)/aug-cc-pVDZ (black squares) levels.

and this is well reproduced by experiment in all matrixes (from 52 to $59 \mathrm{~cm}^{-1}$ ). On the other hand, the theory predicts the two corresponding modes of the $c c$ conformer to be separated only by $3 \mathrm{~cm}^{-1}$ (at 640 and $637 \mathrm{~cm}^{-1}$ ), whereas the experimentally observed frequencies for these two $c c$ bands are separated by about $30 \mathrm{~cm}^{-1}$ in all matrixes (Table 3 , Figure 5). If we compare the relative positions of the predicted vibrations for $c c$ with those predicted for $g c$ and $t c$ and then estimate an expected position for the experimental $c c$ bands relative to the experimental frequencies for the other forms, the $c c$ absorptions should appear within a few $\mathrm{cm}^{-1}$ from $630 \mathrm{~cm}^{-1}$. The experimental band positions are shifted by ca. $15 \mathrm{~cm}^{-1}$ up and down. This behavior persists in all studied matrixes and suggests the existence of some type of resonance interaction between these two modes in the $c c$ conformer. The precise nature of such unexpectedly big splitting may be elucidated by anharmonic calculations, ${ }^{21,22}$ which already reproduced good quantitative correspondence, e.g., with the matrix experimental data on formic acid ${ }^{16}$ and glycine. ${ }^{18}$

Barrier to Intramolecular Rotation. As follows from the analysis of the predicted spectra (Table 3) for the forms $c c$ and $g c$, the lowest vibrational frequencies (43 and $21 \mathrm{~cm}^{-1}$, respectively) correspond to the torsional motion around the central $\mathrm{C}-\mathrm{C}$ bond. This degree of freedom represents the internal coordinate with the highest flexibility in the system. Thus, the barrier to the intramolecular rotation around the central $\mathrm{C}-\mathrm{C}$ bond in the CAA molecule was investigated. During the calculations the value of the $\mathrm{C}-\mathrm{C}-\mathrm{C}=\mathrm{O}$ dihedral angle was incremented and the remaining geometrical parameters were optimized. The result of such calculation is presented in Figure 6 . The chosen reaction coordinate interconnects the three most important stationary points on the potential energy surface of cyanoacetic acid: $c c, g c$, and $t c$. The height of the barrier separating the $c c$ and $g c$ minima does not exceed $3.6 \mathrm{~kJ} \mathrm{~mol}^{-1}$ at both the DFT and MP2 levels of theory. Such a barrier is low enough to allow conformational interconversion in matrixes. In 1984 Barnes collected results of conformational studies in matrixes for molecules exhibiting rotational isomerism ${ }^{23}$ and found a rough empirical correlation between the barrier to internal rotation and the lowest temperature at which interconversion was observed during annealing of the matrixes. Barnes suggested that "at $20 \mathrm{~K}$ a molecule with a barrier to rotation of less than $6 \mathrm{~kJ} \mathrm{~mol}^{-1}$ will be in conformational equilibrium in the matrix".

It seems relevant to make an estimation of the populations of the $c c$ and $g c$ conformers if they are expected to exist in the 
equilibrium after annealing. The $g c$ conformer is doubly degenerated by symmetry (see Figure 6) and $c c$ is not. From the Boltzmann distribution it follows that, if the difference in energies is equal to $1.3 \mathrm{~kJ} \mathrm{~mol}^{-1}$, the equilibrium population of the $g c$ form at $20 \mathrm{~K}$ would be $0.08 \%$ of the $c c$ population. For an energy gap of $1.0 \mathrm{~kJ} \mathrm{~mol}^{-1}$, the population of the $g c$ form at $20 \mathrm{~K}$ would increase to ca. $0.5 \%$ of $c c$. If the energy difference were equal to $0.9,0.8,0.7,0.6$, and $0.5 \mathrm{~kJ} \mathrm{~mol}^{-1}$ the statistical abundance of the $g c$ form would be respectively $0.9,1.6,2.9$, 5.1 , and $9 \%$ of the $c c$ form at $20 \mathrm{~K}$. Let us now check how these numbers correlate with the experiment. In the argon matrix annealed to $20 \mathrm{~K}$ there is a small residual percentage of the $g c$ form, which, however, disappears at a higher temperature, where the equilibrium population should be even higher (Figures 2 and 3 ). In xenon and krypton matrixes, after annealing to $20 \mathrm{~K}$ the $g c$ form is not detectable (Figure 1). Annealing of krypton and xenon matrixes to temperatures higher than $20 \mathrm{~K}$ does not result in the increase of the $g c$-related bands. The implication of these results is either that in the low-temperature matrixes the difference in energies between the $g c$ and $c c$ forms is more than $1 \mathrm{~kJ} \mathrm{~mol}^{-1}$ or that these forms do not exist in the equilibrium in the matrix (these two conditions may also be simultaneously satisfied).

An additional point of interest is the height of the barrier separating the two symmetrically identical $g c$ conformers. The top of the barrier corresponds to the $t c$ form. The possible spectral manifestations of this form were discussed in the preceding section. As calculated at the DFT(B3LYP)/aug-ccpVDZ level, the height of the barrier amounts to $0.10 \mathrm{~kJ} \mathrm{~mol}^{-1}$ (Figure 6), and with the zero-point vibrational energy included, this value increases to $0.27 \mathrm{~kJ} \mathrm{~mol}^{-1}$ (Table 1). It is interesting to note that the lowest vibrational frequency of the $g c$ conformer, calculated at the same level of theory, is equal to $21 \mathrm{~cm}^{-1}$ (Table 3 ), which is equivalent to $0.25 \mathrm{~kJ} \mathrm{~mol}^{-1}$. Thus the first vibrational ground state is at the same level or close in energy to the planar $t c$ configuration and, from the energetical point of view, the practical relevance of the $t c$ form seems to be important even in the gaseous state, because the $\left[g c-t c-g c^{\prime}\right]$ minimum will have the most probable geometry with a planar heavy atom backbone, corresponding to the tc structure.

\section{Conclusions}

The experimental FTIR spectra of cyanoacetic acid isolated in argon, krypton, and xenon matrixes were obtained and interpreted for the first time. Assignment of the spectra was done on the basis of theoretical calculations and annealing experiments. Annealing of the matrixes resulted in a synchronous growth of one set of the bands that can be unequivocally ascribed to the $c c$ conformer. The bands originating from the second conformer present in the gaseous phase, behave in a concerted way during annealing as well: they decrease and finally vanish. During the annealing of the matrixes, a direct interconversion between the two conformers occurs at the monomer level before the formation of aggregates. Annealing of the samples to temperatures above $30 \mathrm{~K}$ allowed us to identify positions of the aggregate bands and led to the assignments of the bands due to the monomeric species. The ground conformational state, both in the gaseous phase and in the matrixes, was identified as the planar $c c$ conformer with the cyano and carbonyl groups in the cis position. The second conformational state in the gaseous phase is predicted as a nonplanar $g c$ conformer with a gauche orientation of the cyano and carbonyl groups. In matrixes, however, this conformational state is either trapped without changing its geometry or undergoes geometrical distortions adopting the $t c$ conformation, which has its heavy atom framework in a planar arrangement to fit better the lattice of the solid host.

Acknowledgment. The financial support of the Fundação para a Ciência e a Tecnologia, Lisbon (grant FCT \#SFRH/BPD/ $1661 / 2000$ and research project POCTI/43366/QUI/2001) is acknowledged. The contribution of S.G.S. and L.A. to this project was supported by a NATO grant.

Supporting Information Available: Animated .gif figures: Figure $1 \mathrm{~S}$, changes in the $\mathrm{C}=\mathrm{O}$ stretching region of the spectrum of cyanoacetic acid isolated in an argon matrix during annealing between 8 and $32 \mathrm{~K}$; Figure $2 \mathrm{~S}$, changes in the $\mathrm{O}-\mathrm{H}$ stretching region of the spectrum of cyanoacetic acid isolated in an argon matrix during annealing between 8 and $32 \mathrm{~K}$; Figure $3 \mathrm{~S}$, changes in the region of the $\mathrm{C}-\mathrm{O}$ stretching $+\mathrm{COH}$ bending vibration in the spectrum of cyanoacetic acid isolated in an argon matrix during annealing between 8 and $32 \mathrm{~K}$.

\section{References and Notes}

(1) Dunkin, I. R. Matrix-Isolation Techniques. A Practical Approach; Oxford University Press: Oxford, U.K., 1998.

(2) Fausto, R., Ed. Low-Temperature Molecular Spectroscopy; Kluwer Academic Publishers: Dordrecht/Boston/London, 1996; Vol. C483.

(3) Reva, I. D.; Plokhotnichenko, A. M.; Stepanian, S. G.; Ivanov, A. Y.; Radchenko, E. D.; Sheina, G. G.; Blagoi, Y. P. Chem. Phys. Lett. 1995, 232, 141-148; Chem. Phys. Lett.. 1995, 235, 617 (Erratum).

(4) Binev, I. G.; Stamboliyska, B. A.; Binev, Y. I. J. Mol. Struct. 1998 , $444,235-245$.

(5) Becke, A. D. Phys. Rev. A 1988, 38, 3098-3100. 789.

(6) Lee, C. T.; Yang, W. T.; Parr, R. G. Phys. Rev. B 1988, 37, 785-

(7) Vosko, S. H.; Wilk, L.; Nusair, M. Can. J. Phys. 1980, 58, 12001211.

(8) Krishnan, R.; Pople, J. A. Int. J. Ouantum Chem. 1978, 14, 91100.

(9) Pople, J. A.; Head-Gordon, M.; Raghavachari, K. J. Chem. Phys. 1987, 87, 5968-5975.

(10) Scuseria, G. E.; Schaefer, H. F., III. J. Chem. Phvs. 1989, 90, 37003703 .

(11) Cizek, J. In Advances in Chemical Physics. Correlation Effects in Atoms and Molecules; Lefebvre, R., Moser, C., Eds.; Interscience Publishers: London, New York, Sydney, Toronto, 1969; Vol. 14, pp 35-89.

(12) Frisch, M. J.; Trucks, G. W.; Schlegel, H. B.; Scuseria, G. E.; Robb, M. A.; Cheeseman, J. R.; Zakrzewski, V. G.; Montgomery, J. A., Jr.; Stratmann, R. E.; Burant, J. C.; Dapprich, S.; Millam, J. M.; Daniels, A. D.; Kudin, K. N.; Strain, M. C.; Farkas, O.; Tomasi, J.; Barone, V.; Cossi, M.; Cammi, R.; Mennucci, B.; Pomelli, C.; Adamo, C.; Clifford, S.; Ochterski, J.; Petersson, G. A.; Ayala, P. Y.; Cui, Q.; Morokuma, K.; Salvador, P.; Dannenberg, J. J.; Malick, D. K.; Rabuck, A. D.; Raghavachari, K.; Foresman, J. B.; Cioslowski, J.; Ortiz, J. V.; Baboul, A. G.; Stefanov, B. B.; Liu, G.; Liashenko, A.; Piskorz, P.; Komaromi, I.; Gomperts, R.; Martin, R. L.; Fox, D. J.; Keith, T.; Al-Laham, M. A.; Peng, C. Y.; Nanayakkara, A.; Challacombe, M.; Gill, P. M. W.; Johnson, B.; Chen, W.; Wong, M. W.; Andres, J. L.; Gonzalez, C.; Head-Gordon, M.; Replogle, E. S.; Pople, J. A. Gaussian98, revision A.11.1; Gaussian, Inc.: Pittsburgh, PA, 2001.

(13) Stepanian, S. G.; Reva, I. D.; Radchenko, E. D.; Sheina, G. G. Vibr. Spectrosc. 1996, 11, 123-133.

(14) Reva, I. D.; Stepanian, S. G. J. Mol. Struct. 1995, 349, 337-340.

(15) Reva, I. D.; Stepanian, S. G.; Adamowicz, L.; Fausto, R. J. Phys. Chem. A 2001, 105, 4773-4780.

(16) Maçôas, E. M. S.; Lundell, J.; Pettersson, M.; Khriachtchev, L.; Fausto, R.; Räsänen, M. J. Mol. Spectrosc. 2003, 219, 70-80.

(17) Pettersson, M.; Lundell, J.; Khriachtchev, L.; Räsänen, M. J. Am Chem. Soc. 1997, 119, 11715-11716.

(18) Stepanian, S. G.; Reva, I. D.; Radchenko, E. D.; Rosado, M. T. S.; Duarte, M.; Fausto, R.; Adamowicz, L. J. Phys. Chem. A 1998, 102, $1041-$ 1054.

(19) Fausto, R.; Maçôas, E. M. S. J. Mol. Struct. 2001, 563, 27-40.

(20) Reva, I. D.; Ilieva, S. V.; Fausto, R. Phys. Chem. Chem. Phys. 2001, 3, 4235-4241.

(21) Bludsky, O.; Chocholousova, J.; Vacek, J.; Huisken, F.; Hobza, P. J. Chem. Phys. 2000, 113, 4629-4635.

(22) Chaban, G. M.; Jung, J. O.; Gerber, R. B. J. Phys. Chem. A 2000, 104, 10035-10044.

(23) Barnes, A. J. J. Mol. Struct. 1984, 113, 161-174. 